\title{
Effectiveness of KMC on Success of Breast feeding in Preterm Low Birth Weight Neonate
}

\author{
Md Mahbubul Hoque*, Nishat Jahan, Md Maksudur Rahman, Liton Chandra Saha, Rowsan Jahan Akhter and \\ MAK Azad Chowdhury \\ Department of Neonatology, Dhaka Shishu Hospital \& Bangladesh Institute of Child Health, Bangladesh
}

Submission: January 31, 2017; Published: March 02, 2017

*Corresponding author: Md Mahbubul Hoque, Professor of Neonatology, Dhak Shishu Hospital \& Bangladesh Institute of Child Health, Bangladesh, Tel: 01729290121; Email: mahbubulhoque2013@gmail.com

\begin{abstract}
Background: Kangaroo mother care (KMC) is a low cost method for care of low birth weight infants particularly for those weighing less than $2000 \mathrm{~g}$ at birth. It includes thermal care through continuous skin-to-skin contact, support for exclusive breastfeeding and prevention of infection.

Objective: To determine whether the implementation of KMC to low birth weight infants would improve early and exclusive breastfeeding.

Materials and methods: A randomized controlled trial was conducted in Dhaka Shishu (Children) Hospital, Bangladesh over 6 months period. Eighty neonates were randomized into KMC group and control group forty in each. Intermittent KMC was given in KMC group with average time of 10-12 hours a day. Neonate in conventional care was managed under radiant warmer and incubator. During hospital stay, both the groups were monitored for daily weight gain by electronic weighing machine, episodes of hypothermia, apnoea, nosocomial infection, physiological parameters (heart rate, respiratory rate, and axillary temperature) and feeding practice. These were measured during hospital stay by the help of a nurse assigned for KMC only.

Results: The mean time of initiation of KMC $1.80 \pm 1.09$ days. Average birth weight of babies in both the groups was between 1200-1400 $\mathrm{gm}$. The mean time to achieve full enteral feeding in KMC group was $9.35 \pm 3.95$ days and in control group $14.35 \pm 6.06$ days (p<0.001). Exclusive breast feeding during discharge was significantly higher in KMC group (38/95\%) than control group (24/60\%) ( $\mathrm{p}<0.001)$. There was also significant higher rate of weight gain in KMC group $(18.35 \pm 7.81 \mathrm{gm})$ than control group $(13.55 \pm 4.89 \mathrm{gm})(\mathrm{p}<0.001)$.
\end{abstract}

Conclusion: KMC is more effective in early establishment of feeding as well as achievement of exclusive breast feeding successfully in preterm babies. Better weight gain and lesser infection are associated benefits.

Keywords: KMC; Breast feeding; Preterm-LBW

\section{Introduction}

A global health recommendation is that infants should be exclusively breast fed for the first six months of life as because breast milk mediates unequalled beneficial effects regarding nutritional, immunological, and cognitive outcomes [1]. This recommendation extends to preterm infants because they are often at increased risk for infections and long-term ill health and because the positive effects of breast milk is even more prominent in these infants [2,3]. Managing these preterm babies are clinically more challenging in initiation and sustainability of breastfeeding as their suckling behavior is not mature and requires neonatal care for a sustainable period. In Bangladesh exclusive breastfeeding rate has declined from 62 to 54 [4] and there is no data on Preterm breastfeeding rate. As PT rate is high in Bangladesh it might have influence on declining exclusive breastfeeding rate [5]. In Sweden and Germany it was found that $3 \%$ to $17 \%$ of the PT infants were breastfed exclusively at 5 or 6 months of corrected age [6]. Transitional process from gavage feeding alone to breastfeeding alone is not smooth. However Kangaroo Mother Care (KMC), which has an extensive research base, is regarded as a successful way to empower mothers to become familiar with their infants, strengthens their mothering at their own pace, and increases breastfeeding rate and duration [7,8]. A few studies from both low and high income countries have shown that preterm babies who experience KMC are breastfed more at discharge compared to those who receive conventional care. 
The aim of this study was therefore to find out the association of KMC with breastfeeding at discharge.

\section{Methods}

This prospective randomized controlled trial was conducted in a tertiary hospital, Dhaka Shishu (Children) Hospital, Dhaka, Bangladesh over 6 months period from August 2014 to January 2015. Babies weighing $1250 \mathrm{gm}$ to $1800 \mathrm{gm}$ and stable were

enrolled for study. Babies with congenital anomalies, birth asphyxia were excluded. After enrollment according to the inclusion and exclusion criteria the subjects were divided into 2 groups: Kangaroo mother care group and conventional care group. Randomization was achieved by simple randomization and allocation was concealed by sealed envelope. KMC was initiated as soon as the baby was stable. Mother/caregivers were counseled and trained on $\mathrm{KMC}$ procedures. Mothers were also trained on how to understand the low body temperature and apnoea of the baby. The mother provided skin to skin contact to the baby in upright position dressed with a cap, socks and diaper and supported in bottom with a sling/binder. Intermittent KMC was given with duration of each period of at least 2 hours and repeated at least six times a day. Adequate privacy was ensured. Comfortable bed or chair was provided. A KMC chart was maintained. Neonate in conventional method care was managed under radiant warmer and incubator.

Data about infant feeding (Time of commencement of first feed, days to achieve full enteral feed, episodes of feed intolerance, rate of exclusive breastfeeding), weight and episodes of problems if any (Hypothermia, sepsis, apnoea) were recorded. These were measured during hospital stay by the help of a nurse. Sign symptoms of sepsis were monitored and if any of the study neonate in either group developed features of sepsis the following investigations were done- complete blood count, CRP, blood culture and sensitivity and other supportive investigations.

Infant in both the groups were discharged when following criteria were achieved: Baby's general health was good, no evidence of infection and no I/V medications. Baby was feeding well and receiving breast milk directly or by cup and spoon gaining weight (at least $15 \mathrm{gm} / \mathrm{kg} /$ day) for 3 consecutive days. Maintaining body temperature well without assistance for at least 3 consecutive days and Mother and family members were confident to care the baby.

\section{Results}

Total 80 preterm babies according to inclusion criteria were randomized into 2 groups - KMC group and Incubator group. Their average age on admission was 1-2 days and $60 \%$ of them were male. Birth weight of $70 \%$ the babies were with-in 12501500 gm in KMC case and $80 \%$ in control group (Table 1).
Table 1: Comparison of Base line datas between $\mathrm{KMC}$ and conventional care group.

\begin{tabular}{|c|c|c|c|}
\hline Variables & $\begin{array}{c}\text { Case } \\
(\mathbf{n = 4 0})\end{array}$ & $\begin{array}{c}\text { Control } \\
(\mathbf{n = 4 0 )}\end{array}$ & p value \\
\hline $\begin{array}{c}\text { Age at } \\
\text { admission } \\
\text { ( mean } \pm \text { SD) }\end{array}$ & $1.80 \pm 1.09$ & $2.10 \pm 1.19$ & $0.244^{\text {ns }}$ \\
\hline $\begin{array}{c}\text { Sex of the baby } \\
\text { No. (\%) } \\
\text { Male }\end{array}$ & $24(60.0)$ & $28(70.0)$ & $0.348^{\text {ns }}$ \\
Female & $16(40.0)$ & $12(30.0)$ & \\
\hline $\begin{array}{c}\text { Birth weight } \\
\text { (gm) }\end{array}$ & $28(70.0 \%)$ & $32(80 \%)$ & $0.127^{\text {ns }}$ \\
$\begin{array}{c}1250-1500 \\
>1500-1800\end{array}$ & $12(30.0 \%)$ & $8(20.0 \%)$ & \\
\hline
\end{tabular}

In 35\% cases of KMC group feeding could have been started earlier in comparison to control group which was 20\%. Rate of exclusive breastfeeding was high in KMC group which was $90 \%$ whereas it was $60 \%$ in control group which was statistically significant ( $\mathrm{p}<0.001)$ (Table 2).

Table 2: Feeding outcome between KMC and conventional care group.

\begin{tabular}{|c|c|c|c|}
\hline $\begin{array}{l}\text { Hospital } \\
\text { Course }\end{array}$ & $\begin{array}{c}\text { Case } \\
(n=40) \\
\text { No. }(\%)\end{array}$ & $\begin{array}{l}\text { Control } \\
(n=40) \\
\text { No. }(\%)\end{array}$ & p value \\
\hline $\begin{array}{l}\text { Start of first } \\
\text { feed on } \\
\text { 1st day } \\
\text { 2-3 days } \\
\text { 4-5 days }\end{array}$ & $\begin{array}{c}14(35.0 \%) \\
20(50.0 \%) \\
6(15.0 \%)\end{array}$ & $\begin{array}{c}8(20.0 \%) \\
20(50.0 \%) \\
12(30.0 \%)\end{array}$ & $0.162 \mathrm{~ns}$ \\
\hline $\begin{array}{c}\text { Episode } \\
\text { of feed } \\
\text { intolerance } \\
\text { Yes } \\
\text { No }\end{array}$ & $\begin{array}{c}8(20.0 \%) \\
32(80.0 \%)\end{array}$ & $\begin{array}{l}12(30.0 \%) \\
28(70.0 \%)\end{array}$ & 0.302 \\
\hline $\begin{array}{l}\text { Time of } \\
\text { achieve } \\
\text { full enteral } \\
\text { feeding in } \\
\text { days }\end{array}$ & $9.35 \pm 3.95$ & $14.35 \pm 6.06$ & $<0.001^{*}$ \\
\hline $\begin{array}{c}\text { Exclusive } \\
\text { breast feeding } \\
\text { Yes } \\
\text { No }\end{array}$ & $\begin{array}{c}36(90.0 \%) \\
4(10.0 \%)\end{array}$ & $\begin{array}{l}24(60.0 \%) \\
16(40.0 \%)\end{array}$ & $<0.001^{*}$ \\
\hline
\end{tabular}

Among the complications apnea was more common in control group though the difference was not significant statistically. Development of sepsis was significantly lower (35\%) in KMC group in comparison to conventional methods (65\%) (Table 3). 
Table 3: Comparison of complications between KMC and conventional care group.

\begin{tabular}{|c|c|c|c|}
\hline $\begin{array}{l}\text { Hospital } \\
\text { course }\end{array}$ & $\begin{array}{c}\text { Case } \\
(n=40) \\
\text { No. }(\%)\end{array}$ & $\begin{array}{l}\text { Control } \\
(n=40) \\
\text { No. }(\%)\end{array}$ & p value \\
\hline $\begin{array}{l}\text { Episodes of } \\
\text { apnoea } \\
\text { Yes } \\
\text { No }\end{array}$ & $\begin{array}{l}10(25.0 \%) \\
30(75.0 \%)\end{array}$ & $\begin{array}{l}14(35.0 \%) \\
26(65.0 \%)\end{array}$ & $0.329^{\text {ns }}$ \\
\hline $\begin{array}{c}\text { Features of } \\
\text { sepsis } \\
\text { Yes } \\
\text { No }\end{array}$ & $\begin{array}{l}14(35.0 \%) \\
26(65.0 \%)\end{array}$ & $\begin{array}{l}26(65.0 \%) \\
14(35.0 \%)\end{array}$ & $0.007^{*}$ \\
\hline $\begin{array}{l}\text { Culture proven } \\
\text { sepsis } \\
\text { Yes } \\
\text { No }\end{array}$ & $\begin{array}{c}6(15.0 \%) \\
34(85.0 \%)\end{array}$ & $\begin{array}{c}8(20.0 \%) \\
32(80.0 \%)\end{array}$ & $0.556^{\mathrm{ns}}$ \\
\hline $\begin{array}{l}\text { Episodes of } \\
\text { hypothermia } \\
\text { Yes } \\
\text { No }\end{array}$ & $\begin{array}{l}10(25.0 \%) \\
30(75.0 \%)\end{array}$ & $\begin{array}{l}16(40.0 \%) \\
24(60.0 \%)\end{array}$ & $0.152^{\text {ns }}$ \\
\hline
\end{tabular}

Babies received KMC started early weight gain and their rate of weight gain was significantly better than babies who received conventional care (Table 4).

Table 4: Showing rate of weight gain between KMC and conventional care group.

\begin{tabular}{|c|c|c|c|}
\hline Variables & $\begin{array}{c}\text { Case } \\
(\mathbf{n = 4 0 )} \\
\text { Mean } \pm \text { SD }\end{array}$ & $\begin{array}{c}\text { Control } \\
(\mathbf{n = 4 0 )} \\
\text { Mean } \pm \text { SD }\end{array}$ & p value \\
\hline $\begin{array}{c}\text { Weight gain } \\
\text { started }\end{array}$ & $6.60 \pm 1.74$ & $8.45 \pm 2.14$ & $<0.001^{*}$ \\
\hline $\begin{array}{c}\text { Birth weight } \\
\text { regained }\end{array}$ & $10.35 \pm 3.09$ & $13.50 \pm 3.70$ & $<0.001^{*}$ \\
\hline Rate of gain & $18.35 \pm 7.81$ & $13.55 \pm 4.89$ & $0.001^{*}$ \\
\hline
\end{tabular}

\section{Discussion}

Although there are countless benefits of breastfeeding for preterm babies, the prevalence of breastfeeding in this group is still not satisfactory. A study showed that among Canadian babies weighing less than $2500 \mathrm{gm}$ only $58 \%$ had been breastfed at birth, compared to $73 \%$ in term group. Among LBW infants only $3 \%$ were discharged on exclusive breastfeeding [9]. Study done in Malaysia showed, only $40.2 \%$ of VLBW babies were being breastfed at the time of discharge from hospital despite breastfeeding incentive programs adopted by the hospital [10]. That means LBW and prolonged hospital stay have negative effect on mother's decision on breastfeeding.
An important mainstay of KMC is encouragement of breastfeeding. In this study we have found that early breastfeeding could have been stared in LBW and VLBW babies who were managed in KMC and also rate of exclusive breastfeeding was found higher in these babies. In $85 \%$ of KMC babies breastfeeding could have been started within 2-3 days of hospital stay when in conventional methods it was $70 \%$. In KMC group $90 \%$ babies were being exclusively breastfed at the time of hospital discharge, whereas this rate was $60 \%$ in babies who were managed in conventional methods. (Table 1 ) This study suggests that mothers who establish a skin-to-skin contact with their preterm babies have a significant higher milk production than the mother who do not. A study from Sweden done by Whitelaw et al found that 71 preterm babies weighing less than $1500 \mathrm{~g}$ submitted to KMC had a two time higher prevalence of breast feeding than the control group at six weeks of life (55 versus 28\%) [11].

Study in India found similar result, in which the frequency of breastfeeding at six weeks rose to $86 \%$ for babies managed in KMC versus $43 \%$ for control babies [12]. One Cochrane Review by Conde-Agudele et al. [13] on three randomized trials found that KMC was a protective factor for exclusive breastfeeding at hospital discharge (RR 0.41; 95\% CI 0.25-0.68) [13]. Udani et al. [14] found that KMC intervention increased exclusive breastfeeding rates in LVW infants -95\% mothers practiced exclusive breastfeeding and $5 \%$ gave mixed feeding [14]. KMC proved to be an ideal stepping towards early and prolonged breastfeeding for preterm infants which has been proved by various studies that reported higher breastfeeding rates ranging from $77 \%$ to $1000 \%$ with $\mathrm{KMC}$ as compared with no-KMC ranging from $42 \%$ to $71 \%$ [15-17]. These prove that KMC has an important role in the maintenance of the mother's lactation. The continuous and intense mother-infant contacts make the mother more sensitive and responsive to the breastfeeding and resulting in increase of milk volume attributed to the increased oxytocin level s during KMC.

Sepsis rate in KMC babies was less (35\%) in this study in comparison to conventional methods (65\%). Ali SM et al found sepsis rate $7 \%$ in KMC babies whereas it was $23 \%$ in conventional babies [18]. Cochrane meta-analysis revealed that KMC was associated with reduction of nosocomial infection/sepsis (RR 0.45, 95\% Cl 0.27to 0.76) [19]. KMC contributes to better hydration of stratum corneum and may be an occlusive factor to promote skin barrier thereby minimizing nosocomial infections. Apneic spells are common in preterm infants due to various environmental and systemic causes. The rate of apneic spells reduces in KMC babies. In our study we have found that LBW babies in KMC had lower incidence of apnea (25\%) as compared to conventional care babies (35\%). Ali SM et al found apneic rate of 2\% in KMC babies whereas it was $14 \%$ in conventional babies [18]. Suman RP et al. [16] found reduced episodes of apnea during KMC when compared to babies in incubator care in their RCT.

Weight gain was significantly higher in KMC babies than the conventional babies ( $\mathrm{p}<001)$. KMC babies also started weight gain 
early $(p<00.1)$ Meta analysis of KMC studies confirmed greater wt gain in KMC infants than in infants not managed in KMC [13].

\section{Conclusion}

Intermittent $\mathrm{KMC}$ is effective in early establishment of feeding as well as achievement of exclusive breast feeding successfully. Better weight gain and lesser infection are associated benefits.

\section{References}

1. Kramer MS, Kakuma R (2002) The optimal duration of exclusive breastfeeding. A systemic review WHO, Geneva, Switzerland, p. 1-52.

2. Gartner LM, Morton J, Lawrence RA, Naylor AJ, Ohare D, et al. (2005) Breatfeeding and the use of human milk. Pediatrics 115(2): 496-506.

3. World Health Organization (2003) Global Strategy for infant and young child feeding.

4. Bangladesh Demographic Health Survey (BDHS).

5. Blencowe H, Cousens S, Oestergaard MZ, Csou D, Moller AB, et al. (2012) National, regional and worldwide estimates of preterm birth rates in the year 2010 with time trends since 1990 for selected countries: a systematic analysis and implications. Lancet 379(9832): 2161-2172.

6. Akerstrom S, Asplund I, Norman M (2007) Successful breast feeding after discharge of preterm and sick newborn infants. Acta Paediatrica 96(10): 1450-1454

7. Feldman R, Eidelman AI, Sirota L, Waller A (2002) Comparison of skin-to-skin (Kangaroo) and traditional care: Parenting outcome and preterm infant development. Pediatrics 110:16-26.

8. Hake-Brooks SJ, Anderson GC (2008) Kangaroo care and breastfeeding of mother-preterm infant dyads 0-18 months: A randomized control trail. Neonatal Network 27(3): 151-159.

9. Lefebvre F, Ducarme M (1989) Incidence and duration of lactational performance among mother of low-birth-weight infants. CMAJ 140(10): 1159-1164.

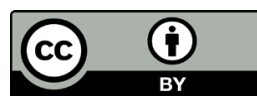

This work is licensed under Creative Commons Attribution 4.0 Licens DOI:10.19080/AJPN.2017.03.555617
10. Boo NY, Goh ES (1999) Predictors of breast feeding in very low birth weight infants at the time of discharge from hospital. L Top Pediatr 45(4): 195-201.

11. Whitelaw A, Heisyerkamp G, Sleath K, Acolet D, Richards M (1988) Skin-to-skin contact for very low-birth weight infants and their mothers. Arch Dis Child 63(11): 1377-1381.

12. Ramanathan K, Paul VK, Deorari AK, Taneja U, George G (2001) Kangaroo Mother Care in very low birth weight infants. Indian J Pediatr 68: 1019-1023.

13. Conde-Agudelo A, Diaz Rosselo JL, Belizan JM (2004) Kangaroo Morther Care to reduce mortality and morbidity in low birth weight infants (Cochrane Review). In: the Cochrane Library (8).

14. Udani RH, Kabra N, Nanavati RN, Aloke VR (2013) Kangaroo Mother Care (KMC): A cohort follow up study on impact of duration of KMC on mortality, morbidity, hospital stay and breastfeeding. Journal of Neonatology 27(1): 5-10.

15. Charpak N, Ruiz JG, Zupan J, Cattaneo A (2005) Kangaroo Mother Care: 25 years later. Acta Paediatrica 94(5): 514-522.

16. Suman RP, Udani R, Nanavati R (2008) Kangaroo Mother Care for low birth weight infants: a randomized control trail. Indian Pediatr 45(1):17-23.

17. Charpak N, Ruiz-Pelaez JG, Figueroa de CZ, Charpak Y (2001) A Randomized Controlled Trial of Kangaroo Mother Care: results of follow-up at 1 year of corrected age. Pediatrics 108(5): 1072-1079.

18. Ali SM, Sharma J, Sharma R, Alam S (2009) Kangaroo Mother Care as compared to conventional care for low birth weight babies. Dicle Med J 36(3): 155-160.

19. Conde-Agudelo A, Diaz Rosselo JL, Belizan JM (2014) Kangaroo Mother Care to reduce mortality and morbidity in low birth weight infants. Cochrane Database Syst Rev 22(4).

\section{Your next submission with Juniper Publishers will reach you the below assets}

- Quality Editorial service

- Swift Peer Review

- Reprints availability

- E-prints Service

- Manuscript Podcast for convenient understanding

- Global attainment for your research

- Manuscript accessibility in different formats

( Pdf, E-pub, Full Text, Audio)

- Unceasing customer service

Track the below URL for one-step submission

https://juniperpublishers.com/online-submission.php 